\title{
Kinetika Reaksi Delignifikasi Campuran Tandan Kosong Kelapa Sawit dan Pelepah Pisang sebagai Bahan Baku Pembuatan Pulp Menggunakan Alat Digester
}

\author{
Azaria Hikmah Fajrianti*1, Indah Purnamasari², Muhammad Yerizam ${ }^{3}$ \\ ${ }^{1,2,3}$ Program Studi Teknologi Kimia Industri, Jurusan Teknik Kimia \\ Politeknik Negeri Sriwijaya, Indonesia \\ Email: ${ }^{1}$ azariahikmah8@gmail.com
}

\begin{abstract}
Abstrak
Pulp adalah hasil pemisahan selulosa dari bahan baku berserat (kayu maupun non kayu) melalui berbagai proses pembuatan baik secara mekanis, semi-kimia dan kimia. Campuran bahan dalam pembuatan pulp yaitu Tandan Kosong Kelapa Sawit (TKKS) dengan kandungan selulosa sebesar 42,7 - 65\% dan pelepah pisang dengan kandungan selulosa sebesar $63-64 \%$. Penelitian ini menggunakan variasi temperatur pemasakan $90^{\circ} \mathrm{C}, 100^{\circ} \mathrm{C}$, $110^{\circ} \mathrm{C}$ dan $120^{\circ} \mathrm{C}$ serta variasi waktu pemasakan selama 60, 75, 90, 105 dan 120 menit. Selain itu juga menggunakan larutan pemasak $\mathrm{NaOH}$ konsentrasi $9 \%$ dengan komposisi sample (TKKS:pelepah pisang) yakni 2:1. Berdasarkan hasil penelitian yang telah dilakukan titik optimum kadar lignin pulp didapatkan sebesar 7,75\% pada waktu pemasakan 90 menit dan temperatur pemasakan $110^{\circ} \mathrm{C}$.
\end{abstract}

Kata kunci: Konstanta Kecepatan Reaksi, Lignin, Orde Reaksi, Pelepah Pisang, TKKS.

\section{Delignification Reaction Kinetics of a Mixture of Oil Palm Empty Fruit Bunches and Banana Stem as a Raw Material for Making Pulp Using Digester Tool}

\begin{abstract}
Pulp is the result of separating cellulose from fibrous raw materials (wood and non-wood) through various manufacturing processes, both mechanically, semi-chemically and chemically. the ingredients in the manufacture of pulp are Oil Palm Empty Fruit Bunches (OPEFB) with a cellulose content of 42.7 - 65\% and banana stem with a cellulose content of $63-64 \%$. This study used variations in cooking temperatures of $90^{\circ} \mathrm{C}$, $100^{\circ} \mathrm{C}, 110^{\circ} \mathrm{C}$ and $120^{\circ} \mathrm{C}$ as well as variations in cooking time for $60,75,90,105$ and 120 minutes. In addition, it also uses a $9 \%$ concentration of $\mathrm{NaOH}$ cooking solution with a sample composition (OPEFB:banana stem) which is 2:1. Based on research that has been done, the optimum point for pulp lignin content is $7.75 \%$ at 90 minutes of cooking time and $110^{\circ} \mathrm{C}$ of cooking temperature.
\end{abstract}

Keywords: Banana Stem, Lignin, OPEFB, Reaction Order, Reaction Rate Constant.

\section{PENDAHULUAN}

Indonesia merupakan produsen kelapa sawit (Crude Palm Oil / CPO) terbesar di dunia, hal tersebut ditandai dengan semakin meningkatnya jumlah luas perkebunan-perkebunan baru. Hal itu secara langsung berpengaruh pada limbah padat yang dihasilkan industri minyak kelapa sawit yaitu Tandan Kosong Kelapa Sawit (TKKS) [1].

1 ton kelapa sawit diketahui akan mampu menghasilkan berupa $23 \%$ atau $230 \mathrm{~kg}$ limbah tandan kosong kelapa sawit, $6,5 \%$ atau $65 \mathrm{~kg}$ sisa limbah cangkang (shell), 4\% atau $40 \mathrm{~kg}$ lumpur sawit (wet decanter solid), $13 \%$ atau $130 \mathrm{~kg}$ serabut (fiber) dan 50\% limbah cair [2]. Tandan Kosong Kelapa Sawit (TKKS) sebagai bahan baku produk berbasis selulosa bisa dimanfaatkan seperti pulp dan juga kertas. Tandan Kosong Kelapa Sawit (TKKS) dipilih karena memiliki kandungan holoselulosa cukup baik yaitu mencapai 65,45\% dengan hemiselulosa sebesar 26,69\% dan selulosa 38,76\% [3]. Kadar lignin yang terkandung pada Tandan Kosong Kelapa Sawit (TKKS) sebesar 22,23\%.

Upaya untuk mengurangi limbah padat lainnya yang kurang dimanfaatkan oleh masyarakat adalah pelepah pisang (Musa paradisiaca L.). Pelepah pisang adalah tanaman dengan umur simpan yang lama, yang di banyak tempat dapat ditemukan sebagai limbah pertanian, serta untuk perolehan ataupun penanganan bahan mengeluarkan biaya yang cukup rendah [4]. Pelepah pisang mengandung $83,3 \% \alpha$-selulosa dan 2,97\% lignin. 
Delignifikasi adalah suatu proses yang sangat penting dalam pembuatan pulp kertas, sebab kadar lignin yang tinggi dalam suatu bahan akan turut mempengaruhi kondisi pemasakan yang diperlukan untuk menyempurnakan proses pemutusan lignin. Hal ini tentu sangat terkait dengan kualitas kertas yang dihasilkan. Kinetika delignifikasi sabut kelapa dapat diketahui dari banyaknya lignin yang dapat diendapkan dari lindi hitam hasil pemasakan untuk setiap waktu pemasakan yang diperlukan, penelitian yang telah dilakukannya menjelaskan bagaimana proses dasar secara kimia yang terjadi pada delignifikasi sabut kelapa dengan proses peroksida alkali yang meliputi mekanisme reaksi, laju reaksi dan tingkat reaksi dari proses delignifikasi tersebut, yang secara umum merupakan suatu proses yang sangat penting dalam upaya pengendalian proses pembuatan pulp (industri kertas), meskipun penelitian dalam skala laboratorium [5].

Untuk beberapa penelitian yang telah mencoba melakukan kajian tentang pembuatan pulp, diantaranya adalah Tarigan (2018) telah melakukan penelitian pembuatan pulp dengan pemanfaatan serat Tandan Kosong Kelapa Sawit (TKKS) pada kondisi perlakuan konsentrasi pelarut KOH 5,6\% dengan waktu pemasakan 45; 60; 75; dan 90 menit mendapatkan kadar lignin sebesar 6\%. Pada penelitian pembuatan pulp dari pelepah pisang yang dilakukan oleh Dewi dkk (2015) pada kondisi perlakuan konsentrasi pelarut $\mathrm{NaOH} \mathrm{3 \%} \mathrm{dengan} \mathrm{waktu}$ pemasakan 128,413 menit menghasilkan sebesar 2,637\% kadar lignin. Lalu pada penelitian pembuatan pulp campuran Tandang Kosong Kelapa Sawit (TKKS) dan pelepah pisang yang dilakukan Fariati (2016) diperoleh konsentrasi optimum pada kondisi perlakuan konsentrasi pelarut $\mathrm{NaOH} 9 \%$ mendapatkan rendemen sebesar 44,42\% sedangkan waktu optimum pemasakan 150 menit mendapatkan rendemen sebesar 45,57\%.

Dari beberapa penelitian diatas yang telah mencoba melakukan kajian tentang pembuatan pulp dari bahan baku Tandan Kosong Kelapa Sawit (TKKS) serta bahan baku pelepah pisang ataupun bahan dasar campuran Tandan Kosong Kelapa Sawit (TKKS) dan pelepah pisang ini masih belum adanya pembahasan mengenai kinetika reaksinya. Maka, pada penelitian ini akan sejalan dengan penelitian sebelumnya yang berorientasi pada pengembangan konsep-konsep dasar kinetika dari suatu proses kimia. Dalam prosesnya agar di dapatkan suatu gambaran yang terjadi secara kimia yaitu delignifikasi campuran Tandan Kosong Kelapa Sawit (TKKS) dan pelepah pisang dalam pembuatan pulp.

\section{METODE PENELITIAN}

\subsection{Waktu dan Tempat}

Pelaksanaan pembuatan alat dilakukan pada bulan April 2021, sedangkan penelitian dilakukan pada bulan Mei-Juli 2021 di Laboratorium Satuan Proses Jurusan Teknik Kimia Politeknik Negeri Sriwijaya Palembang pada pukul 07.00-15.00 WIB.

\subsection{Alat dan Bahan}

Alat yang digunakan yaitu terdiri dari seperangkat alat Digester, pengaduk, spatula, gelas ukur, pipet tetes, kaca arloji, gelas kimia $250 \mathrm{~mL}$, pipet ukur, bola karet, erlenmeyer $1000 \mathrm{~mL}$, erlenmeyer $500 \mathrm{~mL}$, labu takar, corong kaca, cawan porselin, kertas saring $60 \mathrm{~cm} \times 60 \mathrm{~cm}$, kertas indikator $\mathrm{pH}$, bak perendaman, hotplate, oven, waterbath, neraca analitik.

Adapun bahan-bahan yang digunakan yaitu Tandan Kosong Kelapa Sawit (TKKS), pelepah pisang, NaOH, $\mathrm{H}_{2} \mathrm{SO}_{4} 98 \%$, aquadest, air es, air panas.

\subsection{Proses Pembuatan Pulp}

Dalam prosedur percobaan pembuatan pulp yaitu membersihkan sampel Tandan Kosong Kelapa Sawit (TKKS) yang masih kotor dengan mencucinya dengan air bersih mengalir. Lalu mengeringkannya sampai benarbenar kering selama beberapa hari dibawah sinar matahari. Setelah kering, memotong sampel Tandan Kosong Kelapa Sawit (TKKS) tersebut menjadi ukuran kecil supaya memudahkan dalam tahap penghalusan dengan crusher. Untuk sampel pelepah pisang hanya memotongnya menjadi ukuran kecil, kemudian mengeringkannya sampai benar-benar kering selama beberapa hari dibawah sinar matahari dan didapatkan sampel yang garing/renyah jika digenggam. Menghaluskan sampel Tandan Kosong Kelapa Sawit (TKKS) dan pelepah pisang dengan crusher, untuk mendapatkan serbuk/bubuk maka dilakukan pengayakan sampel Tandan Kosong Kelapa Sawit (TKKS) dan pelepah pisang tersebut, lalu menimbang serbuk sebanyak 1 gram untuk menguji dan menganalisa kadar lignin awal pada sampel serbuk tersebut. Untuk pemasakan pulp di dalam alat digester maka menggunakan perbandingan (2:1) serbuk Tandan Kosong Kelapa Sawit (TKKS) dan pelepah pisang, lalu menimbang serbuk sebanyak 248,2436 gram Tandan Kosong Kelapa Sawit (TKKS) dan 83,5505 gram pelepah pisang, kemudian mencampurkan sampel di dalam alat digester dan menghomogenkannya. Menimbang padatan natrium hidroksida $(\mathrm{NaOH})$ sebanyak 327,24 gram, kemudian melarutkan dalam $4.000 \mathrm{~mL}$ aquadest. Lalu, 
memasukkan larutan natrium hidroksida $(\mathrm{NaOH})$ (larutan pemasak) tersebut ke dalam alat digester yang berisikan sampel. Memasak campuran sampel di dalam alat digester. Temperatur pemasakan yang digunakan yaitu $90^{\circ} \mathrm{C}, 100^{\circ} \mathrm{C}, 110^{\circ} \mathrm{C}$ dan $120^{\circ} \mathrm{C}$ dengan konsentrasi larutan pemasak $\mathrm{NaOH}$ yang digunakan yaitu $9 \%$ serta waktu pemasakan yang digunakan yaitu 60, 75, 90, 105, dan 120 menit. Setelah proses pemasakan, mendinginkan sampel. Lalu menyaring dan juga mencuci hasil pemasakan untuk memisahkan black liquor (lindi hitam) serta raw pulp dari sisa hasil pemasakan. Kemudian menganalisa kadar lignin akhir pada pulp tersebut.

\subsection{Pengujian Kadar Lignin}

Adapun prosedur pengujian kadar lignin (metode Klason SNI 0492:2008) yaitu menimbang contoh kayu sebanyak 1 gram atau pulp kering oven sebanyak 2 gram. Memasukkan gelas kimia tersebut ke dalam wadah yang berisikan air es. Memindahkan contoh tersebut untuk kayu ke dalam gelas kimia $50 \mathrm{~mL}$ dan untuk pulp ke dalam gelas kimia $100 \mathrm{~mL}$ lalu kemudian menambahkan $15 \mathrm{~mL}$ Asam Sulfat $\left(\mathrm{H}_{2} \mathrm{SO}_{4}\right) 72 \%$ untuk kayu dan 40 $\mathrm{mL}$ Asam Sulfat $\left(\mathrm{H}_{2} \mathrm{SO}_{4}\right) 72 \%$ untuk pulp. Melakukan penambahan secara perlahan dengan mengatur temperatur $19^{\circ} \mathrm{C}-21^{\circ} \mathrm{C}$ di dalam bak perendaman sambil melakukan maserasi dan pengadukan selama $2-3$ menit menggunakan batang pengaduk. Jika cukup terdispersi, menutup gelas beker menggunakan kaca arloji serta membiarkan selama 2 jam di dalam bak perendaman dan selama proses tersebut berlangsung melakukan sesekali pengadukan. Menambahkan ke dalam erlenmeyer $1.000 \mathrm{~mL}$ untuk kayu dan erlenmeyer $2.000 \mathrm{~mL}$ untuk pulp sebanyak $300 \mathrm{~mL}$ aquadest untuk kayu dan $400 \mathrm{~mL}$ aquadest untuk pulp serta memindahkan secara kuantitatif contoh gelas beker. Menambahkan kembali sampai volume $575 \mathrm{~mL}$ aquadest untuk kayu dan volume $1.540 \mathrm{~mL}$ aquadest untuk pulp, sehingga menjadi 3\% konsentrasi asam sulfat $\left(\mathrm{H}_{2} \mathrm{SO}_{4}\right)$. Kemudian memanaskan sampai mendidih larutan di dalam erlenmeyer tersebut lalu membiarkan selama 4 jam di atas penangas air memakai api kecil. Menjaga agar larutan dalam volume tetap, atau bisa menggunakan pendingin balik. Mendinginkan serta mendiamkan endapan lignin sampai cukup mengendap secara sempurna. Mendekantasikan larutan tersebut lalu memindahkan secara kuantitatif endapan ke dalam corong gelas atau cawan masir dilapisi dengan kertas yang beratnya sudah diketahui. Mencuci sampai bebas asam dengan air panas endapan lignin tersebut (dengan menguji kertas indikator $\mathrm{pH}$ ). Mengeringkan kertas saring atau corong gelas atau cawan masir yang berisi endapan lignin ke dalam oven dengan temperatur $102^{\circ} \mathrm{C}-108^{\circ} \mathrm{C}$. Kemudian mendinginkannya di dalam desikator serta menimbang hingga di dapat berat yang konstan. Perhitungan kadar lignin.

$$
\mathrm{x}=\frac{\mathrm{A}}{\mathrm{B}} \times 100 \%
$$

\section{Keterangan:}

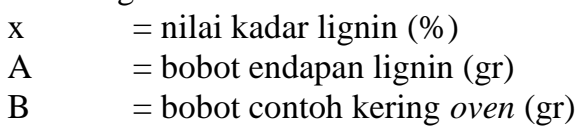

\section{HASIL DAN PEMBAHASAN}

\subsection{Pengaruh Waktu Pemasakan dan Temperatur Pemasakan terhadap Kadar Lignin (\%)}

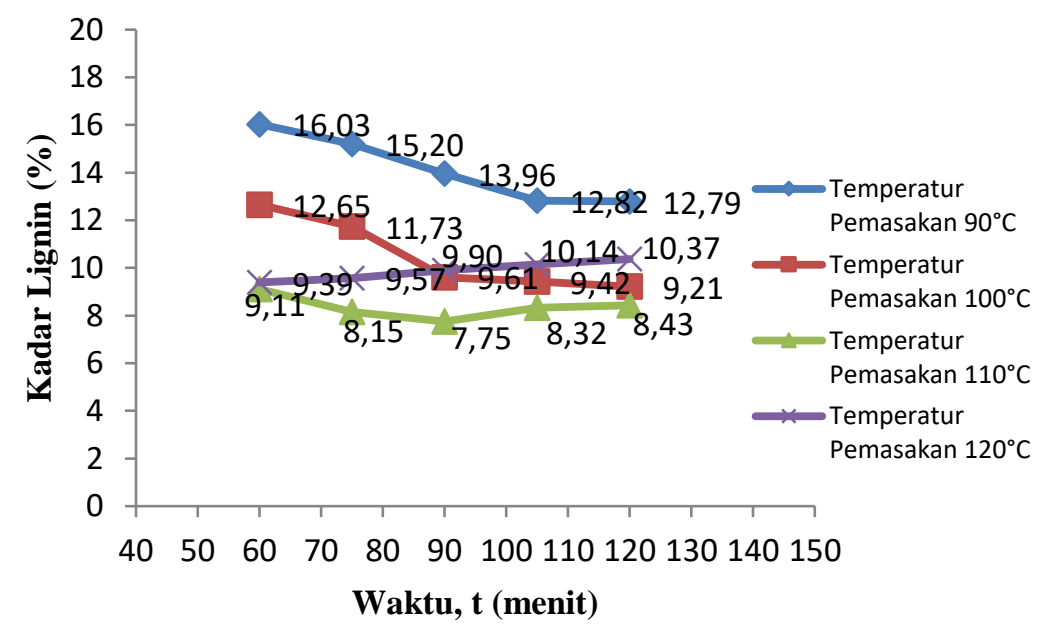

Gambar 1. Grafik Hubungan Waktu Pemasakan dan Temperatur Pemasakan terhadap Kadar Lignin 
Pada Gambar 1 menunjukkan bahwa di dapatkan hasil analisa kadar lignin pulp yang paling tinggi pada awal waktu pemasakan kandungan lignin dalam pulp sebesar 16,03\%, diperoleh lignin pada waktu pemasakan 60 menit dan temperatur pemasakan $90^{\circ} \mathrm{C}$, sedangkan kadar lignin pulp yang didapatkan paling rendah dimana merupakan titik optimum pada waktu pemasakan 90 menit dan temperatur pemasakan $110^{\circ} \mathrm{C}$ sebesar $7,75 \%$, hal ini dapat dilihat bahwa dengan waktu pemasakan yang bertambah, meningkatnya temperatur pemasakan, di dalam cairan pemasak jumlah lignin yang terlarut akan lebih banyak, sehingga kadar lignin akan cenderung menurun. Namun, jika memperpanjang lama pemasakan menjadi 2 jam, akan mengakibatkan kadar lignin pulp kembali naik.

Pada Gambar 1 juga menunjukkan bahwa semakin lama waktu pemasakan dan semakin tinggi temperatur pemasakan, maka kandungan lignin pulp yang dihasilkan akan semakin rendah. Dikarenakan hal ini terjadi selama berlangsungnya reaksi pemasakan telah banyak lignin yang terdegradasi, namun pada temperatur pemasakan $120^{\circ} \mathrm{C}$ dengan waktu pemasakan 120 menit kandungan lignin kembali naik dari rentang 9-10\%. Hal ini juga disebabkan oleh lignin yang mengalami repolimerisasi yakni pembentukan kembali polimer-polimer lignin akibat dari semakin tingginya temperatur pemasakan, sehingga kandungan lignin pun menjadi lebih tinggi.

\subsection{Menentukan Orde Reaksi}

Pada reaksi orde 3 persamaan laju reaksinya adalah:

$$
-\frac{\mathrm{dC}_{\mathrm{A}}}{\mathrm{dt}} \quad=\quad \mathrm{k}_{3} C_{A}^{3}
$$

Persamaan tersebut diintegrasi menjadi:

$$
\begin{array}{llll}
-\int_{\mathrm{C}_{\mathrm{A} 0}}^{\mathrm{C}_{\mathrm{A}}} \frac{\mathrm{dC}_{\mathrm{A}}}{C_{A}^{2}} & = & & \int_{0}^{\mathrm{t}} k_{3} \mathrm{dt} \\
\frac{1}{C_{A}{ }^{2}}-\frac{1}{C_{A 0}{ }^{2}} & = & & 2 \mathrm{k}_{3} \mathrm{t} \\
\frac{\frac{1}{2}}{\left(C_{A}\right)^{2}} & = & \frac{1}{C_{A 0}{ }^{2}}+\mathrm{k}_{3} \mathrm{t}
\end{array}
$$

Maka diperoleh nilai persamaan grafik $\mathrm{y}=\mathrm{Ax}+\mathrm{B}$, dimana $\mathrm{y}=\frac{\frac{1}{2}}{\left(C_{A}\right)^{2}}, \mathrm{~A}=\mathrm{k}_{3} \mathrm{t}$, dan $\mathrm{B}=\frac{1}{C_{A 0}{ }^{2}}$. Dari persamaan 5 dapat dibuat hubungan antara waktu pemasakan terhadap nilai $\frac{\frac{1}{2}}{\left(C_{A}\right)^{2}}$ pada berbagai temperatur pemasakan seperti disajikan pada Tabel 1. Selanjutnya dibuat grafik hubungan antara waktu pemasakan dan temperatur pemasakan terhadap nilai $\frac{\frac{1}{2}}{\left(C_{A}\right)^{2}}$ seperti disajikan pada Gambar 2 .

Tabel 1. Hubungan antara waktu pemasakan terhadap nilai $\frac{\frac{1}{2}}{\left(C_{A}\right)^{2}}$ pada berbagai temperatur pemasakan

\begin{tabular}{ccccc}
\hline \multirow{2}{*}{ Maktu } & \multicolumn{4}{c}{$\mathbf{1 / 2}\left(\mathbf{C}_{\mathbf{A}}\right)^{\mathbf{2}}(\mathbf{m o l} / \mathbf{L})$} \\
\cline { 2 - 4 }$($ Menit $)$ & $\mathbf{9 0}{ }^{\circ} \mathbf{C}$ & $\mathbf{1 0 0}^{\circ} \mathbf{C}$ & $\mathbf{1 1 0}^{\circ} \mathbf{C}$ & $\mathbf{1 2 0}^{\circ} \mathbf{C}$ \\
\hline 0 & 3,2327 & 3,2327 & 3,2327 & 3,2327 \\
60 & 677,7168 & 1088,2640 & 2098,3531 & 1975,0775 \\
75 & 753,7514 & 1265,6665 & 2621,8033 & 1901,4786 \\
90 & 893,6027 & 1885,6824 & 2899,4253 & 1776,8261 \\
105 & 1059,5935 & 1962,5174 & 2515,7569 & 1693,7114 \\
120 & 1064,5700 & 2053,0336 & 2450,5309 & 1619,4137 \\
\hline
\end{tabular}




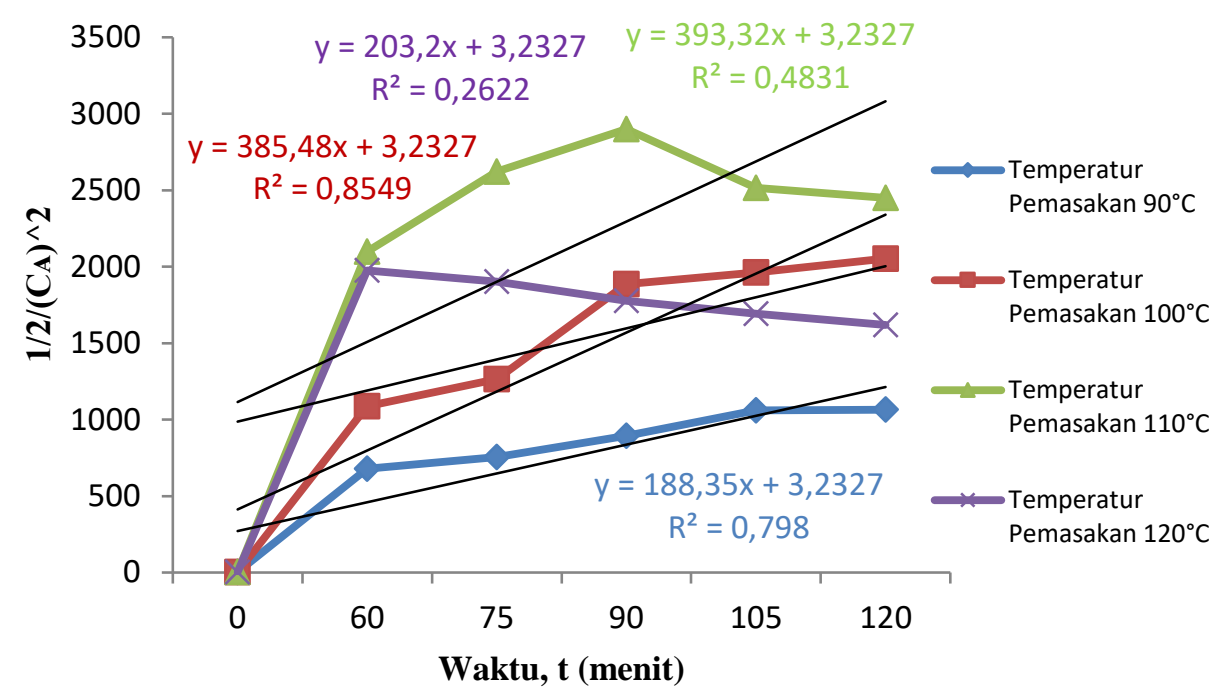

Gambar 2. Grafik Hubungan Waktu Pemasakan dan Temperatur Pemasakan terhadap Nilai $\frac{\frac{1}{2}}{\left(C_{A}\right)^{2}}$

\subsection{Pengaruh Temperatur Pemasakan terhadap Konstanta Kecepatan Reaksi}

Nilai slope dan intercept diperoleh dengan perhitungan excel, nilai $\mathrm{y}=\mathrm{Ax}+\mathrm{B}$ dimana $\mathrm{A}$ (slope) digunakan untuk mencari nilai $-\frac{\mathrm{E}_{\mathrm{a}}}{\mathrm{R}}$ sedangkan B (intercept) digunakan untuk mencari nilai A, karena data yang didapat mengikuti reaksi orde tiga sehingga nilai $\mathrm{k}$ terhadap $\mathrm{T}$ didekati melalui persamaan Arrhenius. Nilai k didapat pada berbagai temperatur pemasakan ditunjukkan seperti pada Tabel 2 .

Tabel 2. Nilai k pada berbagai temperatur pemasakan

\begin{tabular}{cc}
\hline $\begin{array}{c}\text { Temperatur Pemasakan } \\
\left({ }^{\circ} \mathbf{C}\right)\end{array}$ & $\begin{array}{c}\mathbf{k} \\
\left(\text { menit }^{-1}\right)\end{array}$ \\
\hline 90 & 188,35 \\
100 & 385,48 \\
110 & 393,32 \\
120 & 203,2 \\
\hline
\end{tabular}

Nilai k yang diperoleh pada berbagai temperatur dapat digunakan untuk menentukan nilai energi aktivasi (Ea) delignifikasi pada temperatur T, dengan menggunakan persamaan Arrhenius, yaitu:

$$
\mathrm{k}=\mathrm{A} \cdot \mathrm{e}^{-\frac{\mathrm{E}_{\mathrm{a}}}{\mathrm{RT}}}
$$

Apabila disederhanakan, maka persamaannya menjadi:

$$
\ln \mathrm{k}=\quad \ln \mathrm{A}-\frac{\mathrm{E}_{\mathrm{a}}}{\mathrm{R}} \cdot \frac{1}{\mathrm{~T}}
$$

Dimana dapat dihubungkan antara $\ln \mathrm{k}$ dan $\frac{1}{\mathrm{~T}}$, maka akan diperoleh kemiringan yang merupakan $-\frac{\mathrm{E}_{\mathrm{a}}}{\mathrm{R}}(\mathrm{Ea}$ adalah energi aktivasi reaksi yang bersangkutan dan $\mathrm{R}$ adalah konstanta gas ideal) dan perpotongan yang merupakan $\ln \mathrm{k}$. Hubungan $\frac{1}{\mathrm{~T}}$ terhadap nilai ln k dapat dilihat pada Gambar 3 .

Dari grafik hubungan $\frac{1}{\mathrm{~T}}$ terhadap nilai ln $\mathrm{k}$ pada Gambar 3 dapat diketahui bahwa nilai persamaan $\mathrm{y}=\mathrm{Ax}+$ $\mathrm{B}$ dan nilai $\mathrm{R}^{2}$ yaitu $\mathrm{y}=0,0248 \mathrm{x}+5,5585$ sehingga nilai $\mathrm{A}=0,0248$ dan nilai $\mathrm{B}=5,5585$. Dari data tersebut dapat digunakan untuk menghitung nilai A dan nilai Ea sehingga nilai Ea adalah - 0,2061872 dan nilai A yang didapat adalah 361826,1907. Sehingga konstanta kecepatan reaksi (k) dari persamaan Arrhenius adalah k = $361826,1907 . \mathrm{e}^{\frac{0,2061872}{\mathrm{~T}}}$.

Hal tersebut menunjukkan bahwa semakin tinggi suhu reaksi maka jalannya suatu reaksi akan semakin cepat pula. Namun, menurunnya konversi akan terjadi apabila proses berlangsung pada temperatur tinggi [6]. 
Karena reaksi pergerakan bisa berlangsung lebih cepat jika energi kinetik akan melampaui energi aktivasi tersebut [7].

Berdasarkan teori tumbukan, energi aktivasi merupakan terjadinya reaksi apabila tumbukan antar molekul dengan energi yang cukup besar, guna mengawali reaksi serta memutus ikatan, menghubungkan konstanta laju dan energi aktivasi dengan menggunakan persamaan Arrhenius, $k=A \cdot e^{-\frac{E_{a}}{R T}}[8]$.

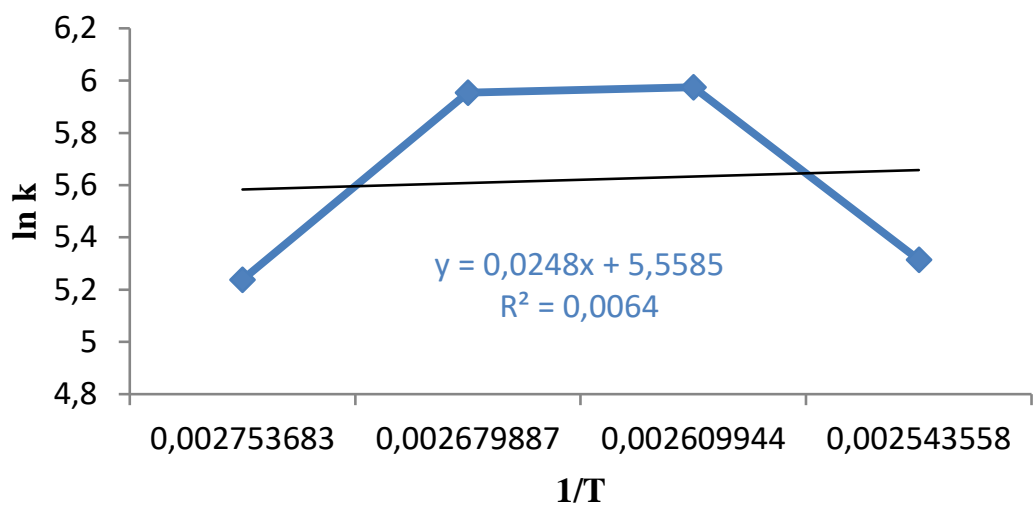

Gambar 3. Grafik Hubungan $\frac{1}{\mathrm{~T}}$ terhadap Nilai ln k

\section{KESIMPULAN}

Berdasarkan hasil penelitian yang telah dilakukan maka dapat diketahui bahwa pengaruh waktu pemasakan dan temperatur pemasakan terhadap kadar lignin yaitu dimana semakin lama waktu pemasakan dan semakin tinggi temperatur pemasakan, maka kandungan lignin pulp yang dihasilkan akan semakin rendah, dengan bertambahnya waktu pemasakan dan meningkatnya temperatur pemasakan, lebih banyak jumlah lignin yang terlarut di dalam cairan pemasak. Orde reaksi delignifikasi campuran Tandan Kosong Kelapa Sawit (TKKS) dan pelepah pisang dalam pembuatan pulp yang didapat mengikuti reaksi orde tiga, karena pada reaksi orde tiga ini nilai k pada berbagai temperatur pemasakan lebih besar dan sudah baik daripada reaksi orde nol, reaksi orde satu maupun reaksi orde dua. Nilai konstanta kecepatan reaksi yang didapat dari hasil penelitian yaitu $\mathrm{k}=$ $361826,1907 . \mathrm{e}^{\frac{0,2061872}{\mathrm{~T}}}$.

\section{DAFTAR PUSTAKA}

[1] DirJen Perkebunan Indonesia. Statistika Perkelapa Sawitan Indonesia (Departemen Pertanian). Jakarta, DirJen Perkebunan Indonesia, 2005.

[2] J. P. Susanto, A. D. Santoso, and N. Suwendi, N, "Perhitungan Potensi Limbah Padat Kelapa Sawit untuk Sumber Energi Terbaharukan dengan Metode LCA," Jurnal Teknologi Lingkungan, vol. 18, no. 2, pp. 165-172, 2017, https://doi.org/10.29122/jtl.v18i2.2046.

[3] Darnoko, "Pembuatan Pulp dari Tandan Kosong Sawit dengan Penambahan Surfaktan," Jurnal Penelitian Kelapa Sawit, vol. 3, no. 1, pp. 75-87, 1995.

[4] I. A. Dewi, A. Ihwah, H. Y. Setyawan, A. A. N. Kurniasari, and A. Ulfah, "Optimasi Proses Delignifikasi Pelepah Pisang Untuk Bahan Baku Pembuatan Kertas Seni," Sebatik, vol. 23, no. 2, pp. 447-454, 2019, https://doi.org/10.46984/sebatik.v23i2.797.

[5] S. Chadijah, "Kinetika Delignifikasi Sabut Kelapa dengan Proses Peroksida Alkali pada Pembuatan Pulp," Jurnal Teknosains, vol. 5, no. 2, pp. 223-231, 2011.

[6] Irmayanti, "Kinetika Reaksi Hidrolisis Pati Talas (Colocasia esculenta) menjadi Etanol dengan cara Fermentasi," Skripsi, 2018.

[7] Haryono, "Analisa Kinetika Reaksi Pembentukan Kerak $\mathrm{CaCO}_{3}-\mathrm{CaSO}_{4}$ dalam Pipa Beraliran Laminar pada Suhu $30^{\circ} \mathrm{C}$ dan $40^{\circ} \mathrm{C}$ Menggunakan Persamaan Arrhenius," Traksi, vol. 17, no. 2, pp. 40-51, 2017.

[8] R. Chang, "Kimia Dasar Konsep-Konsep Inti Edisi Ketiga Jilid 1," Jakarta, Erlangga, 2003. 